\title{
Trabalhando o turismo no contexto escolar: reflexões a partir de experiência no ensino de geografia no município de São João do Cariri (Paraíba/PB, Brasil)
}

\section{Tourism in the school context: reflections from Geography teaching experience in São João do Cariri (Paraíba/PB, Brazil)}

\author{
Luiz Gustavo Bizerra de Lima Morais (MORAIS, L. G. B. de L.) ${ }^{*}$ \\ Ozéas Jordão Silva (SILVA, O. J.) \\ Cleandro Alves de Almeida (ALMEIDA, C. A. de) ${ }^{* * *}$
}

\begin{abstract}
RESUMO - O turismo tomado como temática de trabalho docente aparece em algumas literaturas como mecanismo com múltiplas capacidades de transformar o cenário do ensino de Geografia, permitindo uma leitura espacial capaz de conceber maior dinâmica e sucesso no fazer pedagógico. O objetivo deste artigo é relatar a experiência de trabalho docente que tomou como proposta de ensino o uso do turismo como temática para as aulas de Geografia em uma escola pública localizada no município de São João do Cariri-PB. A metodologia utilizada levou em conta a revisão de literatura e procedimentos metodológicos tais como, exposição dos conteúdos, sucedidos de discussões e desenvolvimento de atividades dentro e fora de sala de aula. Como etapas de fechamento do trabalho foram realizadas um estudo de caso e a exposição dos trabalhos desenvolvidos. Os resultados apontaram que os alunos ampliaram o grau de conhecimento sobre o espaço em que vivem e elevaram a autoestima, bem como, o processo de ensino-aprendizagem mostrou-se fecundo na promoção do exercício da cidadania ao despertar nos alunos o desejo e engajamento em ações na transformação da realidade.
\end{abstract}

Palavras-chave: Turismo; Ensino-aprendizagem; Cidadania.

ABSTRACT - Tourism taken as thematic teaching work appears in some literature as a mechanism with multiple capabilities to transform the landscape of Geography teaching, enabling a spatial reading capable of designing a more dynamic and successful teaching. The objective of this paper is to report the experience of teaching with the propose of using the tourism to teach Geography classes in a public school located in São João do Cariri - Paraíba, Brazil. The methodology was the review of the literature

\footnotetext{
Graduação em Geografia pela Universidade Estadual da Paraíba (UEPB). Endereço para correspondência: Sítio Arara, zona rural. CEP: 58590-000 - São João do Cariri - PB (Brasil). E-mail: luizgustavogeo@hotmail.com

** Graduação em Geografia pela Universidade Estadual da Paraíba (UEPB). Especialização em Metodologia das Ciências pela Universidade Estadual da Paraíba (UEPB) e em Geografia pela Universidade Federal de Pernambuco (UFPE). Mestrado em Ciências da Sociedade pela Universidade Estadual da Paraíba (UEPB). Doutorando em Geografia pela Universidade de Granada - UGR (Espanha), na área de concentração: turismo rural. Professor do Departamento de Geografia da Universidade Estadual da Paraíba (UEPB). Endereço para correspondência: Rua Juvencio Arruda, 240, ap. 303L (Bodocongó). CEP: 584308000 - Campina Grande - PB (Brasil). E-mail: ozeasjordao@ gmail.com.

*** Graduação em Agronomia pela Universidade Federal da Paraíba (UFPB) e em Geografia pela Universidade Estadual da Paraíba (UEPB). Mestrado em Engenharia Agrícola pela Universidade Federal de Campina Grande (UFCG). Endereço para correspondência: Avenida Almirante Barroso, 1674 (Cruzeiro). CEP 58415-670 - Campina Grande, PB (Brasil). E-mail: cleandroalmeida@yahoo.com.br.
} 
and methodological procedures such as description of contents, discussions and the development of activities inside and outside of the classroom. As the closing stages of the work were carried out a case study and exhibition of the work performed. The results indicated that students increased their level of knowledge about the space where they live and raised their self-esteem, as well as the teaching-learning process that demonstrated fruitful in promoting citizenship to awaken in students the desire and commitment on actions to transform reality.

Key words: Tourism; Teaching and learning; Citizenship. 


\section{INTRODUÇÃO}

Tem-se em vista que a perspectiva metodológica que caracteriza o ensino de Geografia na atualidade é a tradicional ancorada, sobretudo, na memorização dos conteúdos que são passados de forma fragmentada pelos professores em sala de aula (MORAIS; SOUSA; SILVA, 2012, p. 4).

A mudança desta realidade é algo a qual precisa ser buscada pelos profissionais compromissados com esta ciência. Para tanto, se faz premente buscar nas diversas áreas do conhecimento e de atuação da sociedade existentes atualmente mecanismos que possam efetivamente mudar este panorama. Uma das alternativas, em meio a tantas existentes, é fazer do processo de ensino aprendizagem, um momento de exercício da cidadania e engajamento na transformação da realidade.

Diante da abrangência de perspectiva e importância que vem assumindo na atualidade o turismo como forma de conservação do patrimônio histórico-cultural e ambiental dos povos, além da perspectiva econômica, seu uso enquanto temática a ser inserida na educação básica passa a ser corrente entre alguns estudiosos especialmente no que diz respeito aos temas transversais.

O turismo acaba por constituir uma temática transversal importante, vislumbrando a abordagem de temas como: cidadania, alteridade, sociabilidade, cultura, educação ambiental e patrimonial que, quase sempre, não encontram espaço nas discussões diárias das disciplinas, assim, “[...] educar visando formar cidadãos críticos e participativos é uma maneira de envolver os educandos nos acontecimentos cotidianos, despertando uma postura ativa e engajada sobre as questões sociais" (FONSECA FILHO, 2007, p. 10).

Diante do que vem sendo levantado, o turismo acaba se tornando uma ferramenta em potencial. Segundo Peccatiello (2005, p. 2), o turismo enquanto temática a ser abordada no contexto escolar destaca-se pela capacidade de "dinamizar as práticas pedagógicas através, principalmente, da vivência que proporciona”.

Trabalhar sobre o contexto do enfoque do turismo consiste em tarefa prazerosa, abrindo perspectivas para a utilização de metodologias que permitam levar o aluno a vivenciar a realidade cotidiana de maneira prática, constituindo uma prática de envolvimento com a própria cultura, além do turismo em si, "formando cidadãos 
responsáveis e protetores de seus patrimônios culturais (patrimônios históricos, culturais, intangíveis e naturais) além de bons anfitriões de visitantes e turistas" (FONSECA FILHO, 2007, p. 31).

A literatura acerca do uso do turismo como ferramenta da aprendizagem, como se destacou, aponta diversas contribuições desta temática, no que diz respeito a dinamização e desenvolvimento de conteúdos em que se tenham em vista a formação plural dos docentes.

Desse modo, este trabalho tem por objetivo relatar a experiência de trabalho docente que tomou como proposta de ensino o uso do turismo como temática para as aulas de Geografia em uma escola pública localizada no município de São João do Cariri no estado da Paraíba (Brasil).

O emprego desta temática no contexto escolar, na forma como se procederam as abordagens em sala de aula, tem especial relevância uma vez que permite aos alunos envolvidos, discutir temas transversais que proporcionam, entre outros aspectos, o fortalecimento de seus laços culturais, a conscientização da necessidade de conservar o patrimônio material e imaterial do seu município e a mobilização social para alcançar tais objetivos.

\section{O MUNICÍPIO DE SÃO JOÃO DO CARIRI E SUAS POTENCIALIDADES TURÍSTICAS}

Mesmo possuindo uma adversidade marcante, o Cariri paraibano é possuidor de belezas naturais diversas, tais como: "forma de vales, serras, plantas e animais, que devem ser preservadas", bem como, suas cidades que são dotadas de um "belo patrimônio arquitetônico e histórico que vale a pena conferir" (FRANCO, 2008, p. 31).

Tais elementos paisagísticos e culturais são peculiares a este ambiente. Pereira e Melo (2008, p. 3-4.) reiteram que os costumes e tradições singulares que apresenta o interior do Nordeste, em conjunto com alguns aspectos naturais característicos, possuem um valor paisagístico muito atrativo para visitantes citadinos. Estes atributos segundo Abílio, Barreto e Feitosa (2010, p. 155) são marcas peculiares do Semiárido paraibano 
que apresenta riquezas naturais singulares, com potencialidades, entre outras, para o turismo ecológico.

Todo este acervo natural-cultural existente ancora-se na concepção de Turismo Sertanejo trazida por Seabra (2001, p. 113), sendo entendido como uma forma característica de lazer que toma como fundamento "a paisagem natural, o patrimônio cultural e o desenvolvimento social" dos espaços sertanejos, tendo por objetivo integrar numa mesma concepção o meio ambiente e suas relações ressaltando "os aspectos naturais, socioeconômicos, culturais e éticos".

Grande parte destes elementos marca a paisagem do município de São João do Cariri. Iniciando-se com os vestígios de sua população pré-histórica em formas de pinturas rupestres gravadas em formações rochosas existentes no espaço rural, formando sítios arqueológicos que evidenciam seu potencial para o turismo (Quadro 1).

QUADRO 1 - SÍTIOS ARQUEOLÓGICOS EXISTENTES NO MUNICÍPIO DE SÃO JOÃO DO CARIRI - PB

\begin{tabular}{|l|}
\hline Sítio Mares - apresenta vários símbolos na cor vermelha de difícil identificação; \\
\hline Sítio Lajedo do Eliseu - com diversos escritos na rocha granítica; \\
\hline Sítio Pedra do Jacó - onde se encontram dois painéis com pinturas; \\
\hline Sítio Jurema - contendo um cemitério humano; \\
\hline Sítio Furnas dos Ossos - além de pinturas rupestres é um cemitério humano; \\
\hline Sítio Picoito - onde podem ser encontradas algumas pinturas em cor vermelha; \\
\hline Serrote dos Letreiros - gravuras sobre blocos de rochas; \\
\hline $\begin{array}{l}\text { Sítio Formigueiro - localizado às margens da estrada PB } 216 \text { - apresenta um painel pintado em } \\
\text { vermelho. }\end{array}$ \\
\hline
\end{tabular}
FONTE: ELABORAÇÃO PRÓPRIA A PARTIR DE ABÍLIO, F. P. et al. (2010), PEREIRA; MELO (2008).

Também podem ser encontradas diversas formações rochosas de especial singularidade paisagística sendo a mais marcante delas a Muralha do Meio do Mundo, localizada às margens da BR 412, “[...] diques de sienito que se estendem como se seguindo uma linha imaginária" (PEREIRA, 2008, p. 55), possuindo um acervo arqueológico de cenário e geologia diferenciada. Cabral (1997, p. 34) assim a descreve: "Estes amontoados de rochas agrupados que se estendem intermitentemente, dentro de uma linha imaginária contínua, formam uma espécie de muralha com uma demarcação que alcançaria mais de 100 quilômetros". Parte da pré-história da sociedade indígena também está gravada nessas rochas, como é o caso do Sítio Picoito que apresenta um painel com diversas pinturas rupestres. 
Outras paisagens expressivas esculpidas pela natureza podem ser encontradas na Serra da Arara, além da própria serra com potencialidade para trilhas ecológicas, a existência de formações rochosas no leito do Rio Soledade confere a Cachoeira do Poço Grande o status de paisagem com potencial turístico. Formada por rochas do tipo Gabro, a cachoeira, assim chamada a queda d'água durante o período chuvoso, fornece aos visitantes um cenário diferenciado.

Por influência das intempéries, sobretudo física provocadas pela ação das águas, as rochas apresentam formas variadas, tais como, escavações naturais em forma de pilões. A existência de paredões de rochas nas margens do rio é outro atrativo que poderia, entre outros fins, ser utilizada para a prática do rapel.

Aspectos dos turismos científico e ecológico podem também ser encontrados no município. O projeto “Água: fonte de Alimento e Renda - uma alternativa sustentável para o semi-árido" é um projeto proposto pela Fundação Centro de Referência em Tecnologias Inovadoras - CERTI e patrocinado pela Petrobrás que visa, a partir do protagonismo da comunidade, atingir o desenvolvimento econômico e social (CERTI, 2013). Para tal, conta com a participação de atores responsáveis pelo suporte técnico, como é o caso da Universidade Federal da Paraíba (UFPB) e da Universidade Federal de Santa Catarina (UFSC).

Tal projeto desenvolve-se a partir da dessalinização de águas subterrâneas servindo tanto para abastecimento humano, como para a produção de peixes e vegetais, especialmente pelo uso de hidroponia (CERTI, 2013). O desenvolvimento da cultura de Spirulina, uma alga com fontes nutritivas e empregadas na alimentação, bem como, o beneficiamento de parte dos produtos na própria comunidade completa o ciclo produtivo que garante renda e melhor qualidade na alimentação das pessoas da comunidade.

Este projeto tem que ser visto por todos como uma forma sustentável de lidar com um ambiente de difícil convívio, como é o caso do bioma Caatinga, marcado pelas intempéries do clima Semiárido e, também, como uma potencialidade turística capaz de atrair renda e sensibilizar turistas quanto a importância de melhores formas de convivência para estes ambientes.

O potencial turístico do município extrapola o espaço rural, pois de acordo com Abílio et al. (2010, p. 54-55): "No meio urbano, merece destaque a Matriz de Nossa 
Senhora dos Milagres, o Sobrado Árabe e o prédio do Mercado Público (museu do Cariri)". Esses prédios históricos, de arquitetura expressiva, fazem parte da história da constituição do Cariri paraibano que correspondem, ao mesmo tempo, páginas importantes da história da Paraíba.

Os aspectos culturais religiosos do município, já se fazem uma prova viva do turismo no município. Mesmo sem as devidas infraestruturas necessárias, tem-se como perceber que o município de São João do Cariri recebe uma vez ao ano um número considerável de pessoas vindas de vários lugares do estado da Paraíba e até de outros Estados para a procissão em homenagem a Nossa Senhora dos Milagres, santa padroeira do município.

A valorização destes potenciais turísticos, “[...] envolvimento, esclarecimento e sensibilização da população, estabelecimento de sistemas de monitoração dos parâmetros de preservação das áreas afetadas, formação e treinamento dos prestadores de serviço, priorizando-se a mão-de-obra local", segundo Pereira (2008, p. 110) e Pereira e Melo (2008, p. 11) são ações que precisam ser desenvolvidas, visando o melhor aproveitamento dos potenciais existentes no município.

\section{MATERIAIS E MÉTODOS}

Visa-se neste momento descrever alguns aspectos que são de suma importância para maior compreensão dos procedimentos tomados durante a realização do trabalho. Para tanto, fez-se necessário uma breve apresentação do espaço e da clientela alvo da discussão. Posteriormente, buscou-se levantar os principais materiais e métodos utilizados durante desenvolvimento do projeto na escola, desde as etapas de planejamento e as de desenvolvimento dentro e fora da sala de aula.

\subsection{ESPAÇO E CLIENTELA PESQUISADA}

A Escola Estadual de Ensino Fundamental e Médio Jornalista José Leal Ramos ou de forma simplificada: E. E. E. F. M. J. José Leal Ramos está localizada no município de São João do Cariri - PB, microrregião geográfica do Cariri Oriental 
Paraibano. Segundo o IBGE (2010), o município possui uma área total é de 653,598 $\mathrm{km}^{2}$, sendo ocupada por 4.344 habitantes (Figura 1).

\section{FIGURA 1 - REPRESENTAÇÃO GEOGRÁFICA DA ÁREA DE ESTUDO}

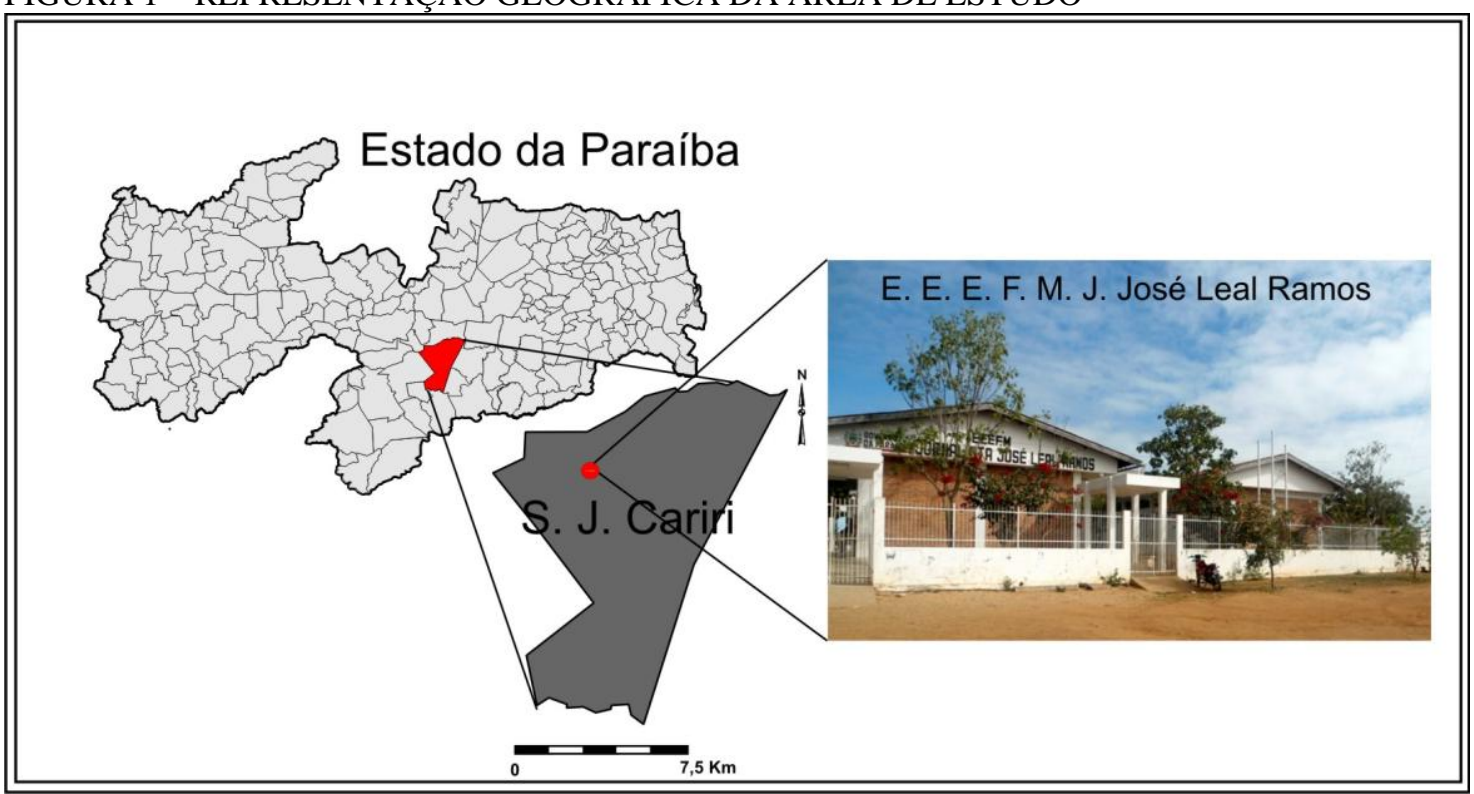

FONTE: ELABORAÇÃO PRÓPRIA (2013).

A E. E. E. F. M. J. José Leal Ramos teve, no início do ano letivo de 2012, 449 alunos matriculados, distribuídos de acordo com as modalidades de ensino regular (Ensino Fundamental e Médio) e Educação de Jovens e Adultos (EJA), sendo ministrados em horários diferenciados, nos períodos matutino, vespertino e noturno (Pesquisa direta, 2012).

A clientela objeto deste relato de experiência foi constituída de alunos do $9^{\circ}$ ano do Ensino Fundamental do turno matutino, compostos por 38 alunos, com idades entre 14 e 17 anos.

\subsection{PROCEDIMENTOS METODOLÓGICOS}

A metodologia de trabalho partiu do levantamento do referencial teórico a respeito da temática a ser abordada, ou seja, o turismo. Isto se deu através de leituras feitas em revistas, livros, jornais, entre outras, que tratavam sobre o assunto. Como técnicas de pesquisa foram utilizadas, conforme Marconi e Lakatos (2003), a observação participante e a observação direta extensiva. 
A partir das leituras se deu a construção de um projeto para se trabalhar a temática em sala de aula, o mesmo foi apresentado a equipe pedagógica da escola para que pudesse ser discutido e implementado.

Após as discussões necessárias entre a equipe pedagógica, o projeto foi apresentado aos alunos, bem como, procedeu-se a divisão da equipe de trabalho (apresentação formal do projeto e divisão da equipe por interesse prévio dos alunos). Para facilitar o desenvolvimento do projeto a turma foi dividida em modalidades de turismo, tais como, turismo rural e urbano.

Foram feitas discussões, em sala de aula, das temáticas específicas a cada área, através de leituras de textos, poesias e uso de imagens. Foram plicados ainda questionários visando saber o conhecimento prévio do aluno. A pesquisa bibliográfica e de campo para enriquecer o conhecimento, bem como, adquirir informações importantes ou registrar fotografias também se fizeram necessárias, tendo em vista levar o conhecimento da teoria à prática.

As pesquisas de campo tiveram por objetivo levantar informações dos equipamentos necessários para dar suporte à atividade turística no município, tais como, quantidade e qualidade dos bares, lanchonetes e pousadas existentes.

Como estratégia para finalizar a primeira parte do projeto foram desenvolvidas atividades de aulas de campo (turismo pedagógico) em locais que apresentavam potencialidades para o turismo. Sendo escolhidos a Muralha do Meio do Mundo e o Projeto Água. Na oportunidade foram discutidas as temáticas abordadas em sala de aula, destacando os pontos positivos e negativos diagnosticados. Os alunos aproveitaram o momento para colher informações e registrar imagens dos locais visitados, bem como, produziram relatório a partir da experiência realizada.

Como última etapa do projeto foi estipulada a apresentação dos trabalhos realizados ao longo do período de vigência do mesmo. Esta etapa consistiu na organização e divulgação das atividades desenvolvidas através da exposição científica e cultural que se realiza anualmente na escola. $\mathrm{Na}$ oportunidade os alunos puderam expor os resultados do projeto como um todo para além dos limites da escola. 


\section{RESULTADOS E DISCUSSÕES}

O turismo está entre as temáticas de maior relevância para o estudo da ciência geográfica, destacando-se a importância dos fluxos de pessoas e as consequências socioambientais para os locais turísticos.

Diante do exposto, o turismo vem como forma de se tratar conceitos e temáticas de âmbito geográfico como paisagem, espaço geográfico, meio ambiente, aspectos naturais e socioeconômicos, relação sociedade/natureza, sentimento de pertencimento, dentre outros, para posteriormente, construir uma atmosfera favorável à aprendizagem e fortalecimento dos laços culturais.

O município de São João do Cariri apresenta uma natureza climática rígida que impõe, a partir das condições socioeconômicas da população, dificuldade na manutenção da subsistência da mesma, fato que vem sendo frequentemente evidenciado por diversos meio de comunicação e até de ensino. No entanto, dessa circunstância de desânimo, surge outra forma de se enxergar este ambiente, pelas características singulares dos aspectos culturais e naturais que podem ser consideradas como potencialidades turísticas.

Foi pensando nesta forma de se olhar o local o qual está inserido o alunado da E. E. E. F. M. J. José Leal Ramos que foi desenvolvido este trabalho. Como público alvo para a aplicação dos conhecimentos geográficos acerca das potencialidades turísticas do município de São João do Cariri, teve-se o $9^{\circ}$ ano do turno manhã, composto por 38 alunos.

O trabalho foi iniciado com a provocação de se pensar a atividade turística no mundo. O exercício mental foi pensar: o que é o turismo? O que possibilita a atividade turística ou o que faz as pessoas se deslocarem de sua residência até um determinado local? O que estas pessoas buscam?

A discussão trazida pelos alunos foi a de que o turismo é um deslocamento de pessoas movido pelo lazer e, portanto, os locais turísticos são dotados de atrativos. A próxima provocação foi imaginar que atrativos estão por trás da atividade turística?

Constatou-se ser a ideia, entre os alunos, da beleza das paisagens, como de fato o turismo se apropria delas para estabelecer suas bases. Dessa forma foi trabalhada, a 
partir da apresentação em Slides, a potencialidade paisagística do município, mostrando diferentes localidades e paisagens existentes no mesmo.

Trabalhou-se primeiramente, as potencialidades paisagísticas existentes no espaço rural enfatizando as disparidades entre as diferentes épocas do ano e o uso adequado para o turismo em cada uma delas.

Os alunos tomaram conhecimento sobre as diversas localidades do município com potencialidades para o desenvolvimento do turismo, tais como: sítios arqueológicos, como os apresentados no Quadro 1 e paisagens expressivas como as existentes na Cachoeira da Serra e a Serra da Arara.

No tocante às paisagens da Muralha do Meio do Mundo, bem como, os demais sítios arqueológicos existentes no município, foi trabalhada a relevância geológica e histórica dos mesmos, especialmente a Muralha do Meio do Mundo pela sua expressividade paisagística e cultural, apresentando no município de São João do Cariri singulares formações geológicas e pinturas rupestres feitas por nativos da região há vários séculos passados. A Serra da Arara é outro elemento de destaque na paisagem do município de São João do Cariri, vários alunos se interessaram em conhecê-la, tendo em vista o conjunto de elementos presentes neste espaço. Suas formações rochosas no leito do rio Soledade constituem paisagens muito diversificadas e para aqueles que se arriscarem a subi-la poderão, através de suas trilhas, encontrar diversos aspectos marcantes da natureza ainda preservada (Figura 2).

FIGURA 2 - (A) SERRA DA ARARA E CACHOEIRA DO POÇO GRANDE; (B) MURALHA DO MEIO DO MUNDO E PINTURAS RUPESTRES.

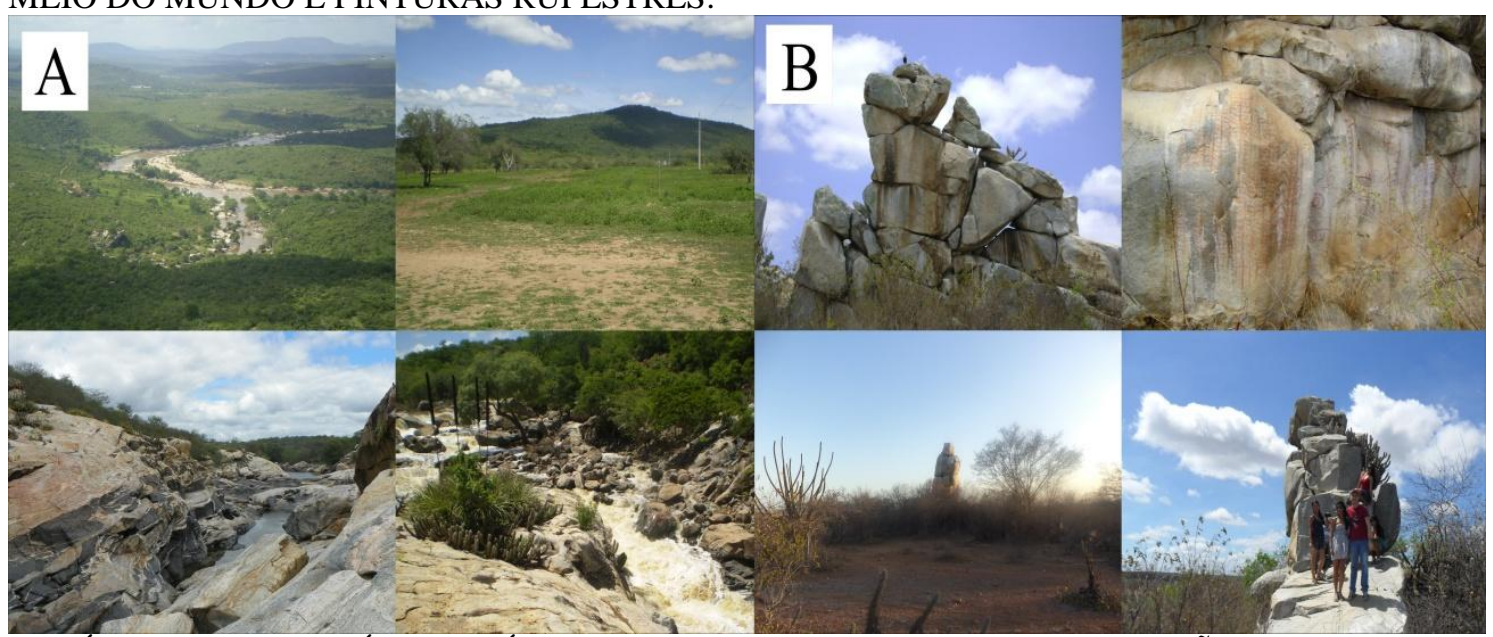

FOTÓGRAFOS: PETRÚCIO CLÉCIO DE OLIVEIRA (2009); OZEAS JORDÃO SILVA (2011); EDILMA DA SILVA SANTOS (2011); OLGA HÉLIA CRUZ PEQUENO (2011). 
Durante a exposição do assunto, através de imagens e discussões a respeito das mesmas, os alunos destacaram a singularidade das paisagens e afirmaram não ter conhecimento de que o município possuía estas belezas. A proposta de estudo sobre as potencialidades turísticas do município despertou o interesse de diversos alunos para conhecer os pontos caracterizados pelas suas paisagens.

No que diz respeito a Serra da Arara, no entanto, para frustração dos alunos, a dificuldade de acesso não abre perspectiva para ser visitada por pessoas que não estejam habituadas a fazerem trilhas na Caatinga, principalmente devido aos perigos que envolvem desde subidas íngremes à presença de animais peçonhentos como cobras.

A partir das discussões os alunos foram instigados a fazerem as leituras das paisagens levando-se sempre em conta os aspectos sociais e naturais das mesmas, tais como: a organização social e cultural dos habitantes, o relevo, a hidrografia e principalmente, as característica da vegetação da Caatinga que pode ser considerada como uma das mais relevantes do mundo.

Não se perdeu de vista, durante o debate que se desencadeou, o enfoque ambiental, pois, levar os alunos a perceber a complexidade do bioma onde estão inseridos conduz necessariamente à necessidade de alertá-los ao manejo sustentável deste, visando a sua preservação e uso racional. Eles tomaram ciência que, somente a partir destas atitudes é que se pode ter em vista um projeto turístico para estes lugares.

Como exemplo prático de relação harmoniosa entre o homem e o meio colocouse para os alunos o Projeto Água existente na comunidade rural de Uruçu. As primeiras discussões versaram sobre a sustentabilidade e os elementos tecnológicos existentes neste projeto, elementos estes que contrariam a lógica da realidade econômica das comunidades circundantes e confere uma importância ambiental ímpar ao projeto.

Como forma de enriquecimento da aprendizagem acerca do conteúdo em estudo, foi proposta uma visita ao projeto, com escala na Muralha do Meio do Mundo. A escolha destes espaços se deu tendo em vista os mesmos englobarem algumas das questões principais que estão em torno do turismo, como preservação ambiental e convivência harmoniosa com a natureza, potencialidades paisagísticas do espaço rural Semiárido e cultura dos povos. Neste momento do trabalho é importante registrar que se constatou haver o entusiasmo da turma. 
Encerrando-se parcialmente as discussões acerca do turismo rural, partiu-se para as potencialidades do setor urbano. No tocante a este assunto, um dos principais pontos trabalhados foi o da riqueza arquitetônica da cidade. Durante as aulas foram apresentados os seus principais prédios históricos. Na oportunidade foi ressaltado o estilo de grande parte das construções ser de arquitetura barroca (Figura 3).

FIGURA 3 - POTENCIALIDADES TURÍSTICAS DO ESPAÇO URBANO DE SÃO JOÃO DO CARIRI-PB

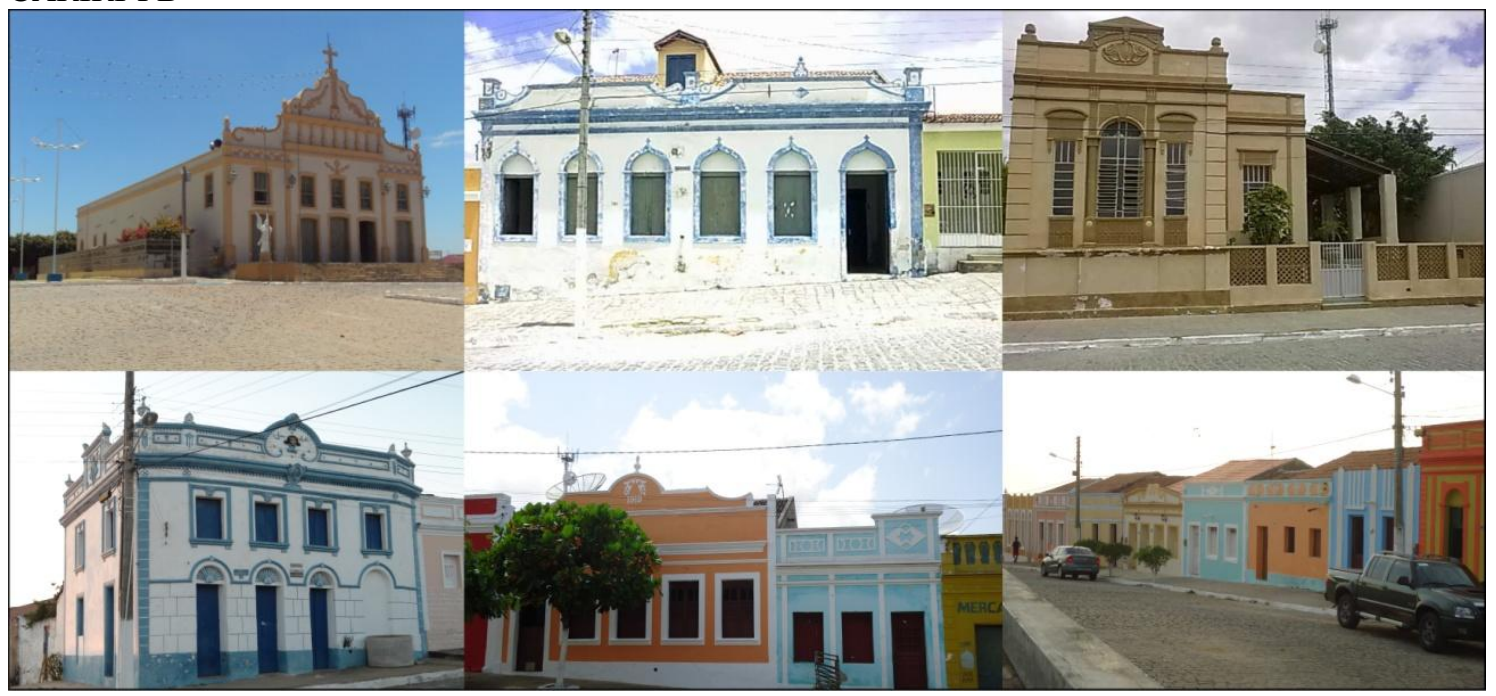

FOTÓGRAFOS: LUIZ GUSTAVO BIZERRA DE LIMA MORAIS (2012); MARIA DO SOCORRO RAMOS (2012).

A preservação do acervo arquitetônico foi um dos pontos chave da discussão, pois, os alunos destacaram que algumas construções antigas da cidade passaram por reformas, perdendo assim, os padrões arquitetônicos originais. Aproveitou-se a oportunidade para evidenciar os principais exemplos de descaso com a conservação dos padrões originais do que pode ser considerado como cartões postais do município.

Os alunos foram instigados a refletir sobre a necessidade da preservação da história local para que se possa ter um uso turístico dos potenciais urbanos. Tal preservação passa primeiramente pela conservação do patrimônio histórico arquitetônico.

As manifestações folclóricas da região, em particular do município, também fizeram parte destas discussões, lendas como a da Comadre Fulozinha da botija e do carro do batuque, entre outras, foram tratadas como riquezas imateriais que necessitam permanecer vivas. Nesta parte das discussões os alunos mostraram-se entusiasmados 
para contar "causos" que se passaram com familiares ou pessoas conhecidas envolvendo alguns dos elementos míticos.

Em se tratando de crença, o caririzeiro possui grandes manifestações, principalmente no que diz respeito aos aspectos religiosos. A Festa de Nossa Senhora dos Milagres, grande manifestação religiosa do Cariri paraibano, tem como momento principal a procissão em homenagem a Nossa Senhora dos Milagres, padroeira do município e da região do Cariri. Este momento é sem dúvida o maior acontecimento turístico do espaço urbano do município de São João do Cariri (Figura 4).

FIGURAS 4 - PROCISSÃO REALIZADA DURANTE OS FESTEJOS EM HOMENAGEM A NOSSA SENHORA DOS MILAGRES NO MUNICÍPIO DE SÃO JOÃO DO CARIRI

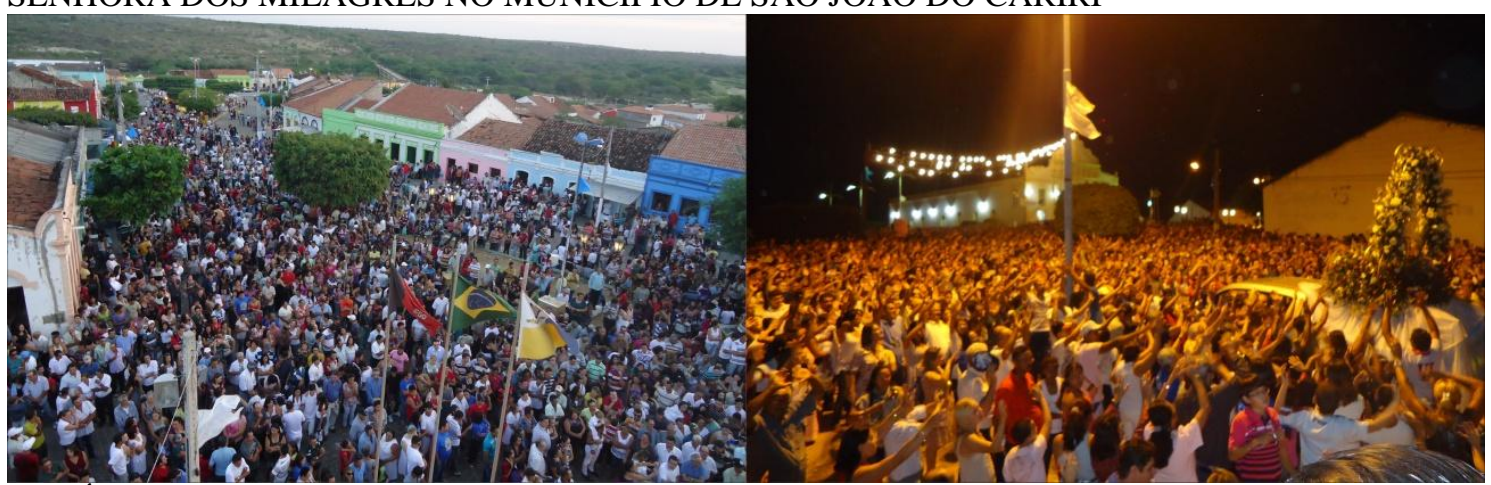

FOTÓGRAFO: MATEUS DE SOUSA COSTA (2011).

Sobre este evento, os alunos destacaram a importância não só cultural como também, econômica para o município. A título de exemplo no ano de 2012 o evento atraiu mais de 20 mil pessoas entre fiéis e curiosos de vários lugares da Paraíba e até de outros Estados para participar da procissão em homenagem a padroeira do município (FESTPB, 2013). Pode-se dizer a partir deste fato que, comerciantes de diversos setores do comércio foram beneficiados com a realização do evento.

Outro ponto, cuja importância não poderia deixar de ser ressaltada para os alunos, foi o da promoção do nome da cidade através deste evento, constituindo-se como um dos principais elementos que caracteriza a cidade.

\subsection{AULA DE CAMPO OU TURISMO PEDAGÓGICO}

Uma das atividades chave desenvolvida no projeto diz respeito à aula de campo ou turismo pedagógico que convergiu todas as temáticas trabalhadas durante sua 
vigência. A viagem foi planejada para que os alunos assumissem o papel de turistas dentro do próprio município em que estavam morando, diferentemente da ideia das aulas de campo desenvolvidas pelas escolas que, quase sempre, procuram mostrar o que há de interessante em outros municípios, não fortalecendo os seus aspectos socioculturais e naturais.

A aula realizou-se no dia 19 de Outubro de 2012 e contou com a presença de 35 alunos dos 38 envolvidos no projeto, 3 professores, a vice-diretora da escola e um funcionário destinado a prestar assistência durante o trajeto.

A saída se deu às 14h30min da E. E. E. F. M. J. José Leal Ramos em direção ao Projeto Água Fonte de Alimento e Renda: uma alternativa sustentável para o Semiárido, localizado na comunidade rural de Uruçu. Durante o percurso os alunos puderam perceber as problemáticas ambientais ocasionadas pela ação humana que confere aos espaços aos quais lhes foram mostrados diversos focos de desertificação.

Ao chegar à comunidade de Uruçu evidenciou-se a surpresa expressa nos rostos dos alunos que, mesmo residindo não muito distante da localidade, não tinham ideia do que se tratava o Projeto Água. Os temas desenvolvidos durante esta etapa da aula apresentaram um caráter interdisciplinar e várias das temáticas trabalhadas em sala foram abordadas durante a visita, mostrando-se muito satisfatórios os resultados. O interesse dos alunos se aguçava a cada etapa da visita ao projeto realizado pela comunidade rural de Uruçu, desde o processo de dessalinização da água ao de culturas hidropônicas realizado em estufas (Figura 5).

FIGURA 5 - (A) DESSALINIZADOR; (B) CULTURAS CULTIVADAS A PARTIR DA ÁGUA DESSALINIZADA ATRAVÉS DE HIDROPONIA

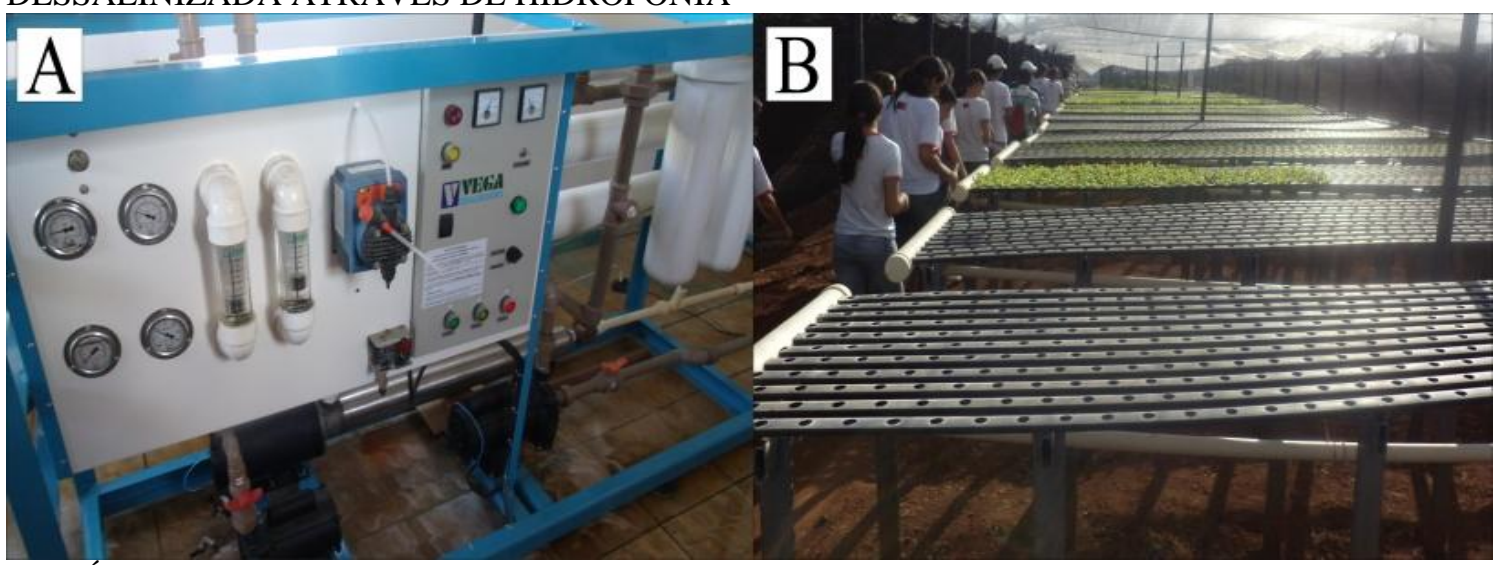

FOTÓGRAFO: ELAYNE BEATRIZ DE FARIAS PEREIRA (2012). 
Os alunos que ainda não acreditavam ser possível produzir alimento em grande escala no Cariri paraibano viram que a partir do emprego de técnicas avançadas toda uma realidade pode ser transformada e logo passaram a questionar os velhos discursos acerca da região, discursos estes de seca e fome.

Saindo do Projeto Água, a aula prosseguiu para outro ponto com potencialidades turísticas e importância histórica, o qual, a maior parte dos alunos ainda não tinha conhecimento de sua relevância e existência. No local conhecido como a Muralha do Meio do Mundo eles foram levados a imaginar como viviam as primeiras civilizações existentes neste ambiente.

As curiosidades maiores se deram em torno das pinturas rupestres, da formação geológica da Muralha, ou seja, como se deu seu surgimento e sobre os nativos que haviam pintado aquelas rochas. Este momento foi oportuno para discutir a existência de vários outros sítios arqueológicos, bem como, da presença de outros monumentos geológicos não só no município, mas, em toda microrregião do Cariri (Figura 6).

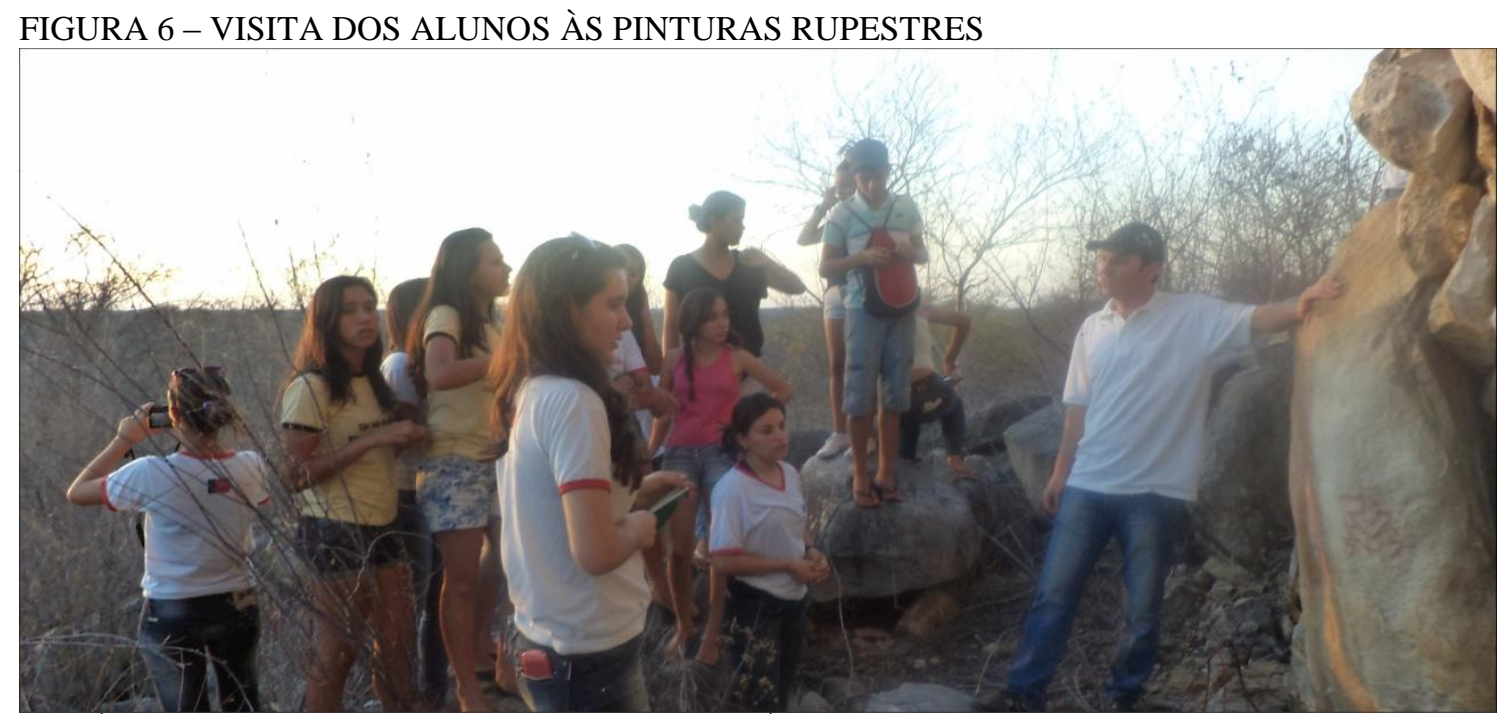

FOTÓGRAFO: ADENOU DANTAS DE FARIAS JÚNIOR (2012).

Foi explicitado que, se eles sentiam-se muito satisfeitos com o que haviam visto ao longo do turismo pedagógico, outras pessoas também poderiam gostar bastante de visitar estas localidades, portanto, constatou-se ser o turismo uma possibilidade para o município, embora isto passe despercebido para os governantes, pois, fizeram algo para promover estas potencialidades para o desenvolvimento turístico do município. 
O retorno dos alunos a E. E. E. F. M. J. José Leal Ramos foi ao final da tarde, observou-se que o semblante dos mesmos mostrou que eles estavam satisfeitos com o momento vivido, podendo ser considerado exitoso todos os momentos da aula. Na volta à sala de aula os alunos estavam na incumbência de entregar um relatório das observações que foram vivenciadas durante o percurso das visitas as localidades e, ainda, começar a preparação para expor os trabalhos na exposição científica da escola.

\subsection{EXPOSIÇÃO CIENTÍFICA}

A exposição científica da escola ocorreu no dia 23/11/2012. O dia anterior foi destinado para que os alunos organizassem os materiais e as salas em que seriam expostos. Tais materiais resultaram de trabalhos realizados pelos próprios alunos e professores ao longo das aulas, sendo essenciais os oriundos da aula de campo, cujos registros fotográficos e outros materiais que puderam conseguir durante e após a sua realização, formaram a base da exposição por parte dos alunos envolvidos no projeto (Figura 7).

FIGURA 7 - (A) BANNERS PRODUZIDOS A PARTIR DE FOTOGRAFIAS DOS ALUNOS; (B) MATÉRIAIS CEDIDOS PELO PROJETO ÁGUA; (C) COMIDAS TÍPICAS DO CARIRI.

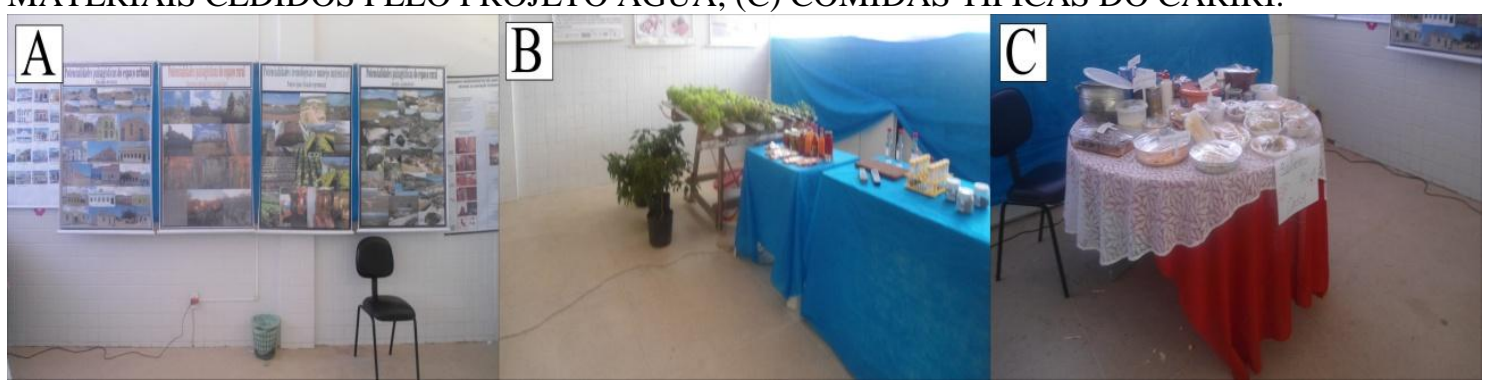

FOTÓGRAFO: PETRÚCIO CLÉCIO DE OLIVEIRA (2012).

Neste momento considerado especial, os alunos apresentaram aquilo que de melhor representam as potencialidades turísticas do município, como paisagens urbanas e rurais marcantes, aspectos históricos e culturais, comidas típicas e os exemplos de uso sustentável dos recursos naturais (Figura 8). 
FIGURA 8 - APRESENTAÇÃO DOS TRABALHOS DURANTE A EXPOSIÇÃO CIENTÍFICA E CULTURAL

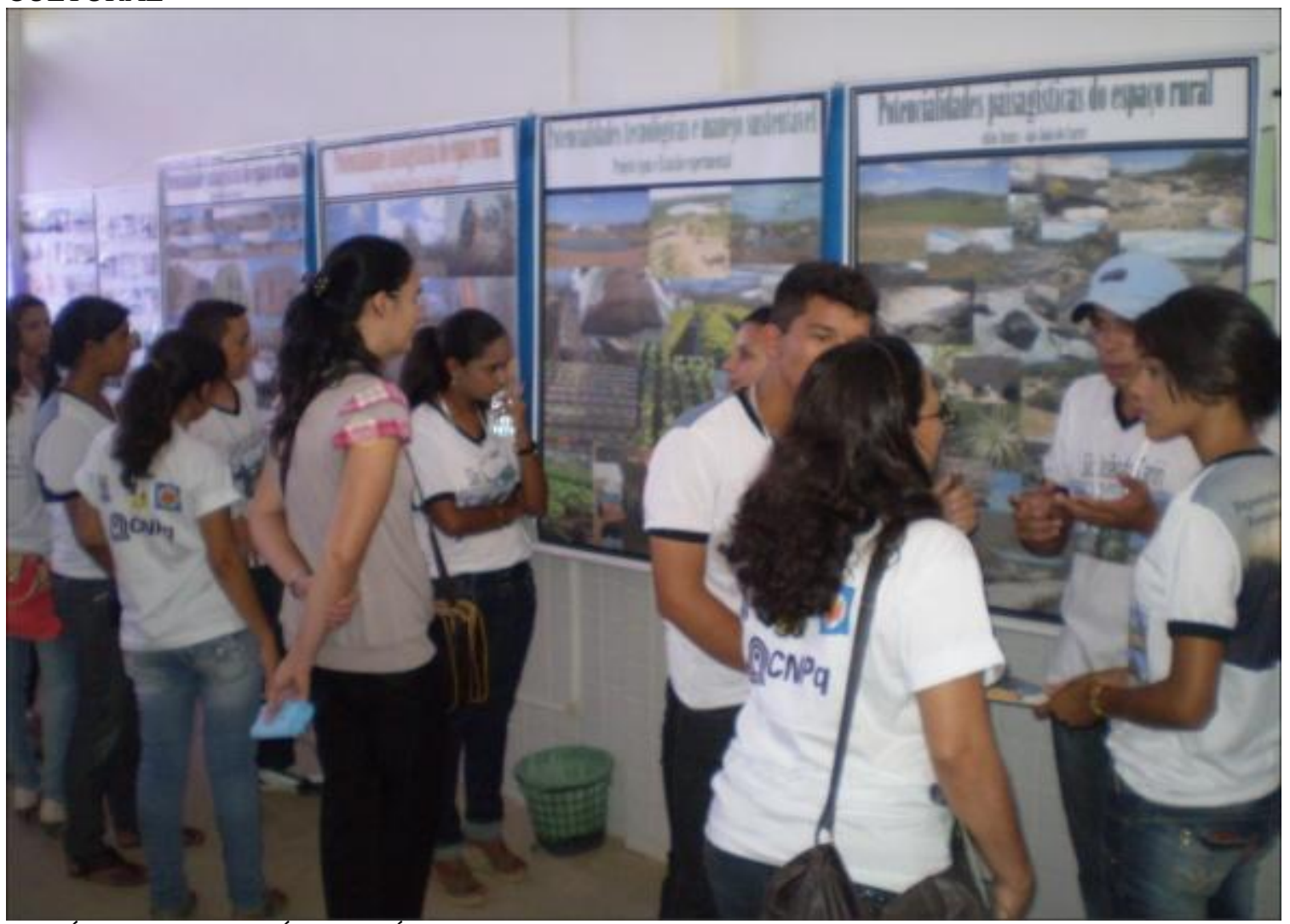

FOTÓGRAFO: PETRÚCIO CLÉCIO DE OLIVEIRA (2012).

A interação com o público se deu de modo muito efetiva, muitas pessoas vindas de outras cidades e do próprio município demonstraram estar surpreendidas com os elementos presentes no município que eram, para muitos até então, desconhecidos. A ideia traçada foi a de que os alunos pudessem passar o máximo possível do encantamento deles ao conhecer estes espaços, para as pessoas que viessem visitar a sala "São João do Cariri: potencialidades turísticas e culturais - um convite ao turismo", tendo como objetivo sensibilizar as pessoas para ter um olhar diferenciado sobre o município de São João do Cariri, espaço de vivência desses alunos.

\section{CONSIDERAÇÕES FINAIS}

Durante as aulas direcionadas ao trabalho da temática: potencialidades turísticas no município de São João do Cariri percebeu-se maior participação entre os alunos que passaram a interagir mais efetivamente nas discussões trazidas para a sala de aula. 
A experiência permitiu aos alunos ampliarem os seus graus de conhecimento sobre o espaço em que viviam, adquirindo novas concepções e elevando as suas autoestimas.

A visita às localidades, alinhada a ideia de um turismo pedagógico, constituiu uma atividade de grande importância, além do prazer de estarem conhecendo locais com paisagens marcantes, em que vivenciaram o conhecimento de modo interdisciplinar.

A exposição científica foi o momento no qual os alunos demonstraram os conhecimentos que haviam aprendido durante a realização do projeto, mostraram desenvoltura nas apresentações e proporcionaram momentos de discussão com os visitantes que, assim como os alunos, ficaram surpreendidos em saber dos potenciais turísticos existentes no município.

O professor não pode perder a oportunidade e a perspectiva de fazer do processo ensino-aprendizagem, um momento de exercício da cidadania e despertar nos alunos o desejo e o engajamento em ações na transformação da realidade.

Considera-se que os resultados positivos deste trabalho permitem afirmar que uma pequena semente foi plantada ao longo do trabalho: que o turismo pode vir a ser nas mãos desses futuros agentes transformadores uma realidade para os espaços do município, tendo em vista o aproveitamento racional dos aspectos marcantes da paisagem e cultura local.

\section{REFERÊNCIAS}

ABÍliO, F. J. P.; MARACAJÁ FILHO, N; RUFFO, T. L. de M. PEQUENO, O. H; GRANJEIRO, Z. T.; ARAÚJO, F. T.; ALCÂNTARA, H. M.; RAMOS, M. S. M. P.; RAMOS, M. S. C.; ARAÚJO, J. F. A.; CHARARA, F. M. N.; ARAÚJO, P. J. Cariri paraibano: história, arqueologia e cultura. In. ABÍLIO, F. J. P. (Org.). Educação ambiental: formação continuada de professores no bioma Caatinga. João Pessoa: Editora Universitária da UFPB, 2010. p. 43-78.

ABÍLIO, F. J. P.; BARRETO, A. de L. P.; FEITOSA, A. A. F. M. A. Convivência no Semi-árido: as populações humanas no contexto do bioma Caatinga. In: ABÍLIO, F. J. P. (Org.). Bioma Caatinga: ecologia, biodiversidade, educação ambiental e práticas pedagógicas. João Pessoa: Editora Universitária da UFPB, 2010. p. 149-170. 
CABRAL, E. M. O potencial arqueológico do Cariri. In: CABRAL, E. M. (org.). Os Cariris Velhos da Paraíba. The Cairis Velhos of Paraíba. João Pessoa: União Editora/Editora Universitária, 1997. p. 29-43.

CERTI. Fundação Centro de Referência em Tecnologias Inovadoras. Santa Catarina. Disponível em: < http://www.certi.org.br/projetos-inovadores/agua-fonte-dealimento-e-renda-petrobras-ambiental.html >. Acesso em: 16-01-2013.

FESTPB. Disponível em:

<http://www.festpb.com/v2/ler_noticia.asp?idnoticia=3622>. Acesso em: 16-01-2013.

FONSECA FILHO, A. da S. Educação e turismo: reflexões para elaboração de uma educação turística. Revista Brasileira de Pesquisa em Turismo, São Paulo, v. 1, n. 1, p. 5-33, setembro 2007.

FRANCO, E. S. Os discursos e contra-discursos sobre a algarobeira (Prosopissp) no Cariri paraibano. 2008. 97 f. Tese de doutorado em Recursos Naturais Universidade Federal de Campina Grande, Campina Grande, 2008.

IBGE. Censo demográfico 2010 - Resultados gerais da amostra. Rio de Janeiro. Disponível em: 〈http://www.ibge.gov.br/cidadesat/topwindow.htm?1>. Acesso em: 1601-2013.

MARCONI, M. A.; LAKATOS, E. M. Fundamentos de metodologia científica. São Paulo: Atlas, 2003.

MORAIS, L. G. B. L.; SOUSA, F. F.; SILVA, H. V. Construção de conceitos geográficos: a percepção dos alunos do ensino fundamental do município de São João do Cariri-pb. In: III COLÓQUIO BRASILEIRO EDUCAÇÃO NA SOCIEDADE CONTEMPORÂNEA, 7., 2012, Campina Grande. Anais... Campina Grande: Secreti, 2012. p. 1-13.

PECCATIELLO, A. F. O. Turismo pedagógico como uma estratégia de ensinoaprendizagem sob a óptica dos Parâmetros Curriculares Nacionais $3^{\circ}$ e $4^{\circ}$ ciclos do Ensino Fundamental. Global Tourism, v. 2, p. 1-19, nov. 2005.

PEREIRA, R. A. Turismo e desenvolvimento local nos Cariris Velhos: uma alternativa à melhoria da qualidade de vida no semi-árido. Caminhos de Geografia, Uberlândia, v. 9, n. 28, p. 96-113, dez. 2008. 
; MELO, J. A. B. de. Ecoturísmo nos Cariris Velhos: uma possiblidade de reestruturação socioeconômica para o Semi-árido brasileiro. Global Tourism, v. 4, n.1, p. 01-14, mai. 2008.

SEABRA, G. de F. As Rotas Culturais do Turismo Sertanejo. Conceitos (João Pessoa), João Pessoa, v. 5, n. 7, p. 113-117, 2001.

Recebido em: 28-03-2013.

Aceito para publicação em: 27-04-2013. 